\title{
Thermal Diffusivity of Linear Alkanes and its Behaviour with the Size of the Chain: Study with a Photopyroelectric Technique
}

\author{
José Abraham Balderas López ${ }^{1}$, Benjamín Rosales Guzmán², Mónica Rosalía Jaime Fonseca ${ }^{3}$ \\ and Joel Díaz Reyes*4 \\ ${ }^{1}$ Department of Basic Sciences, National Polytechnic Institute, Mexico \\ ${ }^{2}$ University of Papaloapan, Institute of Biotechnology, Mexico \\ ${ }^{3}$ National Polytechnic Institute, CICATA. Av. Legaria 694, Col. Irrigation, Mexico \\ ${ }^{4}$ National Polytechnic Institute, CIBA. Ex-Hacienda de San Juan Molino. Km. 1.5 of the Santa Inés Tecuexcomac-Tepetitla State Highway. \\ Tepetitla, Mexico
}

*Corresponding author: Joel Díaz Reyes, National Polytechnic Institute, CIBA. Ex-Hacienda de San Juan Molino. Km. 1.5 of the

Santa Inés Tecuexcomac-Tepetitla State Highway, Tepetitla, Tlaxcala 90700, Mexico

\section{ARTICLE INFO}

Received: 幽 March 13, 2020

Published: 幽 May 26, 2020

Citation: José Abraham BL, Benjamín Rosales G, Mónica Rosalía JF, Joel Díaz R. Thermal Diffusivity of Linear Alkanes and its Behaviour with the Size of the Chain: Study with a Photopyroelectric Technique. Biomed J Sci \& Tech Res 27(5)-2020. BJSTR. MS.ID.004571.

Keywords: Linear Alkanes; Photothermal Techniques; Thermal Characterization

\begin{abstract}
Thermal transport properties of substances are fundamental for science and engineering. Among these properties, thermal diffusivity characterizes the way materials transport heat under non-stationary conditions. The manner in which this thermal property behaves with the size or molecular configuration is very important to understand the mechanisms involved in heat transport. It is a complicated work to study variations on this thermal property taking these two variables (size and configuration) together. Linear alkanes have essentially the same spatial configuration, varying only the molecular size (the number of involved carbon atoms in the molecule), so they are ideal substances to study the behavior of thermal properties with the molecular size alone. In this work photopyroelectric technique, taking the sample's thickness as variable (the so-called TWRC method), is used for thermal diffusivity measurements of linear alkanes, from 1-heptane to 1-heptadecane. It is shown that this thermal property increases with the molecular size. This behavior can be explained in a very simple way if it is considered that the increase in molecular size increases "routes" of heat transport.
\end{abstract}

\section{Introduction}

The knowledge of thermal properties, especially for substances in liquid phase, is very important since this state of matter is widely used in industry, particularly as heat exchangers. The knowledge of these properties is also important in basic science since this information can be used to support theoretical schemes concerning molecular configurations, for instance. Under this perspective is interesting to figure out how the size or molecular configuration influences thermal properties. Photopyroelectric (PPE) techniques are now widely used for thermal characterization of liquids; this can be done by measuring thermal diffusivity, effusivity and specific heat [1-5]. PPE techniques, taking the sample's thickness as variable (the so-called Thermal Wave Resonator Cavity (TWRC)) [4,5], provides high-precision measurements of thermal diffusivity, for which is ideal to carry out empirical studies about the influence of size or molecular configuration on this thermal property. However, the ideal situation is when this study is carry out taking only one of these two possible variables andlinear alkanes result in ideal substances since these organic molecules have a tree configuration with chemical formula $\mathrm{C}_{\mathrm{n}} \mathrm{H}_{2 \mathrm{n}+2}$, where $\mathrm{C}$ atoms are the vertebral column of the structure. With this idea in mind, the TWRC 
method is used for measuring the thermal diffusivity for a series of linear alkanes, from 1-heptane to 1-heptadecane, to figure out the influence of the molecular size on this thermal property.

\section{Theoretical Considerations}

Figure 1 shows a cross section of the PPE experimental setup for thermal diffusivity measurements. Monochromatic radiation, at fix modulation frequency $\mathrm{f}$, strikes a thin silicon slab; thermal waves (temperature fluctuations) generated inside this material travel to the liquid sample and reach the pyroelectric material (a thin PVDF foil). The signal is proportional to the average temperature inside the pyroelectric material. At this way solving the corresponding set of differential equations to find the temperature profile inside the pyroelectric sensor and under the appropriate experimental conditions. It can be shown that, if the liquid sample's thickness, $\mathrm{l}$, is took as variable this photopyroelectric signal takes the very simple form: $V(l)=H e^{-o s}$, where $\sigma=(1+i)(\pi f / \alpha)^{1 / 2}$ is a complex parameter involving sample's thermal diffusivity and $\mathrm{H}$ is a complex expression which is independent of the sample's thickness [4,5]. Linear fits to the amplitude and phase of this equation renders parameter $M$, from which sample's thermal diffusivity can be obtained as $\alpha=\pi f / M^{2}$.

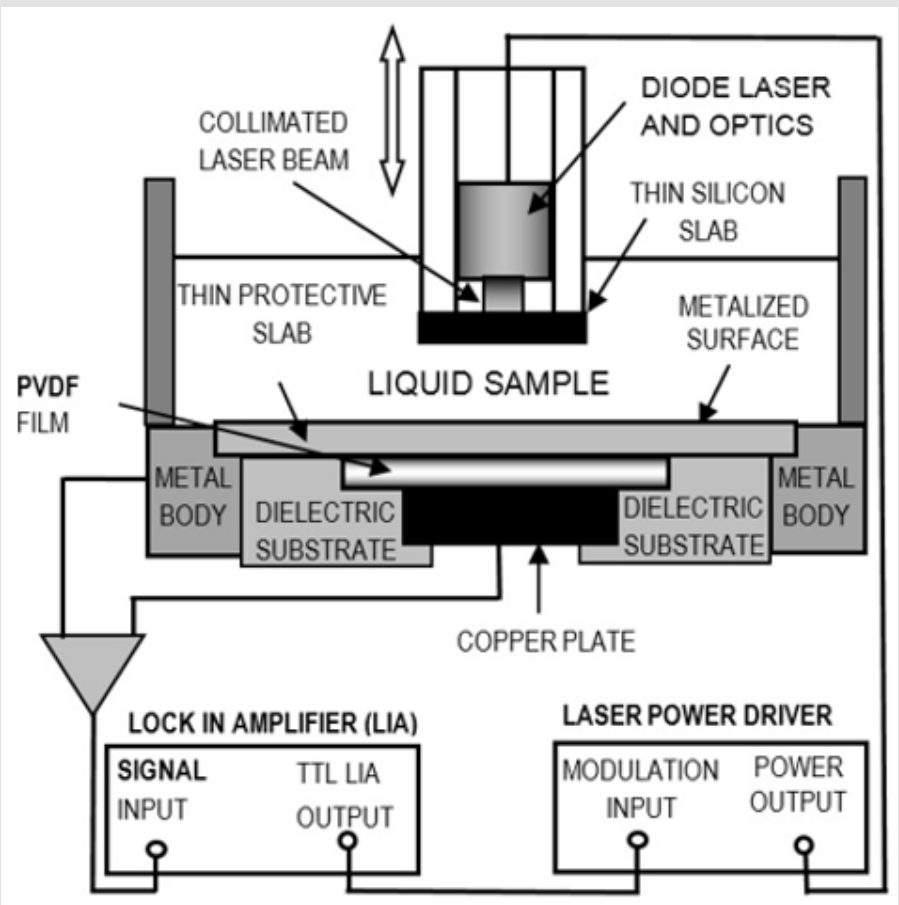

Figure 1: Cross section of the Photopyroelectric (PPE) set up for thermal diffusivity measurements.

\section{Experimental Procedure}

Table 1: Thermal diffusivities, $a$, for the ten linear alkanes studied in this work.

\begin{tabular}{|c|c|}
\hline Alkane & $\boldsymbol{\alpha}\left(\mathbf{c m}^{\mathbf{2}} \mathbf{s}\right)$ \\
\hline 1-heptane & $0.000721 \pm 0.000005$ \\
\hline 1-octane & $0.000746 \pm 0.000006$ \\
\hline 1-nonane & $0.000753 \pm 0.000006$ \\
\hline 1-decane & $0.000761 \pm 0.000006$ \\
\hline 1-undecane & $0.000765 \pm 0.000006$ \\
\hline 1-dodecane & $0.000770 \pm 0.000006$ \\
\hline 1-tridecane & $0.000777 \pm 0.000006$ \\
\hline 1-tetradecane & $0.000788 \pm 0.000005$ \\
\hline 1-pentadecane & $0.000788 \pm 0.000006$ \\
\hline 1-heptadecane & $0.000798 \pm 0.000006$ \\
\hline
\end{tabular}

Ten linear alkanes, from 1-heptane to 1-heptadecane (Table 1), (column 1) were taken for the study. Thermal diffusivity measurements were carried out making the analysis on a set of 10 experimental data. These data consisted of PPE voltage amplitude for ten liquid sample'sthicknesses, taken at increments of 0.0050 $\mathrm{cm}$. Approximately $2 \mathrm{ml}$ of liquid sample was required for each thermal diffusivity measurement. Linear fits were done to obtain slopes $\mathrm{M}$ for each sample from which the corresponding thermal diffusivity was calculated. All measurements were made at a fix modulation frequency of $1 \mathrm{~Hz}$, setting the lock-in's time constant at $3 \mathrm{~s}$ and at room temperature of $23^{\circ} \mathrm{C}$.

\section{Experimental Results}

(Figure 2) shows the linear behaviour of the photopyroelectric amplitude, as a function of the sample's thickness, for 1-undecane. The continuous line in this figure is the best linear fit as to obtain the parameter M, from which sample's thermal diffusivity can be obtained, as it was described above. All analytical procedures were carried out using commercial analytical software (Origin 6.1 ${ }^{\mathrm{TM}}$ ) and 
the corresponding uncertainties were estimated by means of the usual formulas for error propagation. Thermal diffusivity values for all samples are summarized in (Table 1 ), column 2. (Figure 3 ) shows samples' thermal diffusivities as a function of the molecular size. It is evident that this thermal property increases with molecular size.

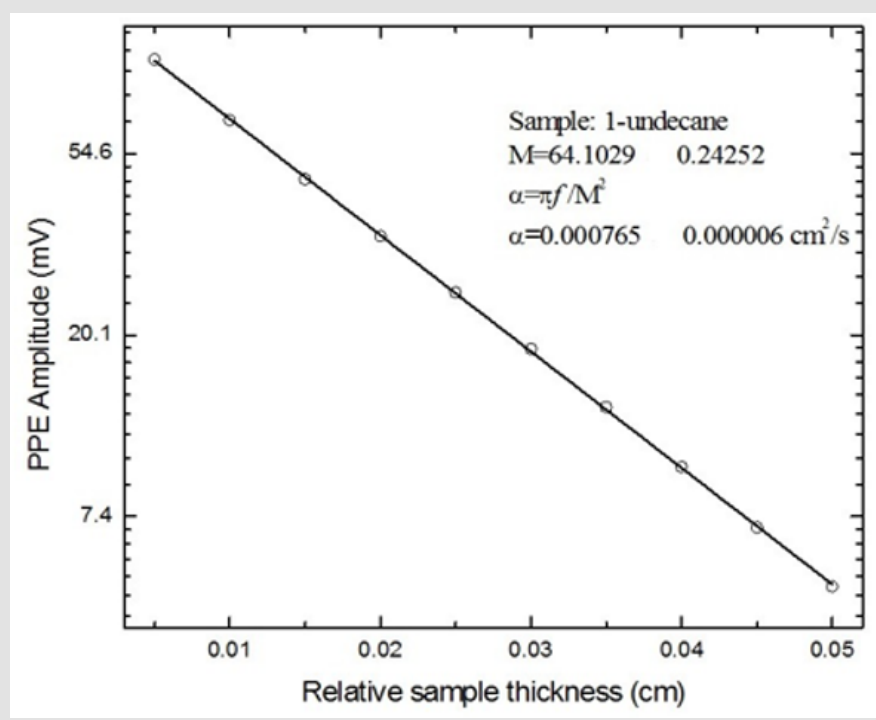

Figure 2: Photopyroelectric amplitude, as a function of the sample's thickness, for 1- undecane. The continuous line represents the best linear fit as to obtain parameter M, from which sample's thermal diffusivity can be obtained.

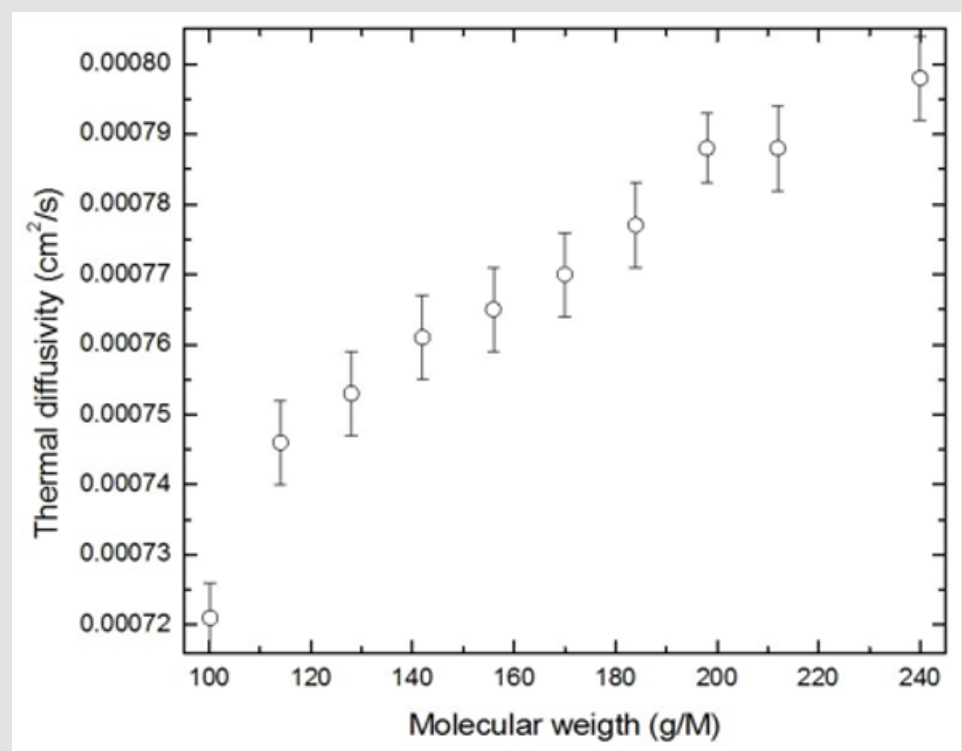

Figure 3: Thermal diffusivities, as a function of the sample's molecular weight, for the 1- alkanes studied in this work.

\section{Conclusion}

Photopyroelectric techniques (TWRC) were shown adequate for measuring thermal properties of 1-alkanes. It was empirically demonstrated that this thermal property increases with the molecular size, if molecular configuration is unchanged. This behaviour could be explained in a very simple form if it is considered that for this kind of molecules heat transport is due to vibrations or rotations of the $\mathrm{C}$-H bonds. Increment of the molecular size increases the number of these bonds, providing at this way more "routes" of heat transport to the molecule and the final effect is an increment in thermal diffusivity. Similar behaviour forthermal conductivity could be expected, as suggested from thermal conductivities reported for 1-butane, 1-heptane and 1-decane [6]. The monotonic behaviour of this thermal property for 1-alkanes contrast with the one reported for 1-alcohols [7], which are linear molecules that differs from 1-alkanes only in an additional $\mathrm{OH}$ radical at one end.

Thermal diffusivity decreases in this case with the molecular size, but this happens only for the first 5 alcohols (from methanol to 1-pentanol) then, starting at 1-hexanol, this thermal property increases with the increase of the molecular size. This peculiar behaviour of thermal diffusivity for linear alcohols can be explained as a "competition" of thermal properties between the $\mathrm{OH}$ - radical 
and the $\mathrm{CH}$ chain. For lineal alcohols of small size thermal diffusivity is driven for the $\mathrm{OH}$ radical meanwhile that for those ones of high molecular weight this thermal property is driven for $\mathrm{CH}$ bonds. In linear alkanes, the monotonic behaviour in thermal diffusivity can be then attributed to the thermal properties of the $\mathrm{CH}$ bonds and the chain's size. These kind of molecules (alkanes and alcohols could be also used to figure out in what manner the molecular configuration influences the thermal properties) and the corresponding results could be complemented with computational simulations.

\section{References}

1. Fuente R, Mendioroz A, Apiñaniz E, Salazar A (2012) Simultaneous Measurement of Thermal Diffusivity and Optical Absorption Coefficient of Solids Using PTR and PPE: A Comparison. Int J Thermophys 33: 18761886.

2. Balderas López JA (2007) Thermal effusivity measurements for liquids: A self-consistent photoacoustic methodology. Rev Sci Instrum 78: 064901.

ISSN: $2574-1241$

DOI: $10.26717 /$ BJSTR.2020.27.004571

Joel Díaz Reyes. Biomed J Sci \& Tech Res

CC (i) This work is licensed under Creative

Submission Link: https://biomedres.us/submit-manuscript.php
3. Delgado Vasallo O, Marín E (1999) The application of the photoacoustic technique to the measurement of the thermal effusivity of liquids. J Phys D: Appl Phys 32(5): 593.

4. Balderas López JA, Mandelis A, García JA (2000) Thermal-wave resonator cavity design and measurements of the thermal diffusivity of liquids. Rev Sci Instrum 71: 2933.

5. Balderas López JA, Jaime Fonseca MR, Gálvez Coyt G, Muñoz Diosdado A Díaz Reyes J (2015) Generalized Photopyroelectric Setup for ThermalDiffusivity Measurements of Liquids. Int J Thermophys 36(5-6): 857861.

6. Poling Bruce E, Prausnitz John M, O’Connel John P (2001) “The properties of gases and liquids", Fifth edition. McGraw-Hill: New York. pp. 768.

7. Balderas López JA, Jaime Fonseca MR, G Gálvez Coyt, Muñoz Diosdado A, Pescador JA, et al. (2018) Photothermal Techniques for Thermal Characterization of Linear Alcohols. Int J Thermophys 39: 111.

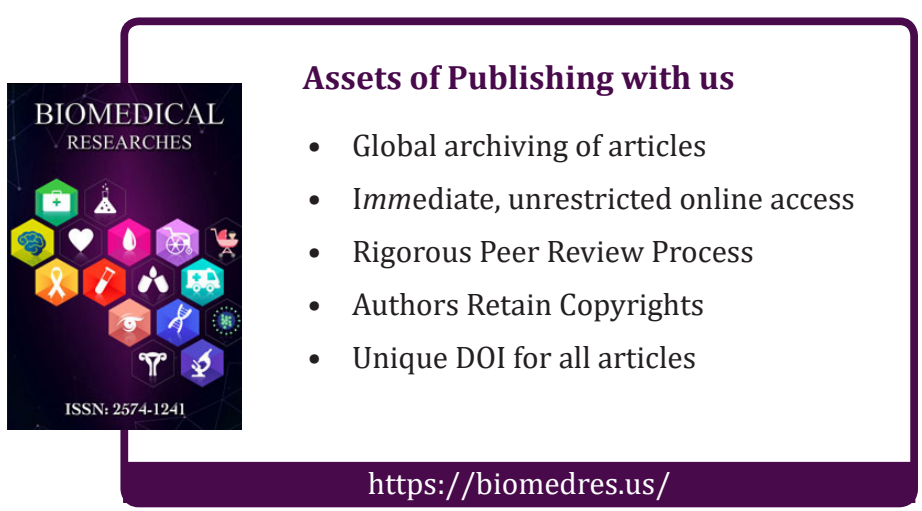

